\title{
Heparin alleviates LPS-induced endothelial injury by regulating the TLR4/MyD88 signaling pathway
}

\author{
WENXUN LIU ${ }^{1,2}$, YAN LI ${ }^{1,2}$, ZHAOZHAO WU ${ }^{3}$, KERONG HAI $^{2,4}$, \\ YUN WANG ${ }^{2,4}$, XIAOHONG ZHOU ${ }^{2,4}$ and QINGSHAN YE YE $^{2,4}$ \\ ${ }^{1}$ Anesthesia Specialty, Ningxia Medical University, Yinchuan, Ningxia 750004; \\ ${ }^{2}$ Department of Anesthesiology, People's Hospital of Ningxia Hui Autonomous Region, Yinchuan, Ningxia 750002; \\ ${ }^{3}$ Department of Anesthesiology, Northwest Minzu University, Lanzhou, Gansu 730030; \\ ${ }^{4}$ Ningxia Anesthesia Clinical Medical Research Center, Yinchuan, Ningxia 750002, P.R. China
}

Received May 31, 2021; Accepted August 13, 2021

DOI: $10.3892 / \mathrm{etm} .2021 .10833$

\begin{abstract}
Heparin is a commonly used in the clinic, however, Heparin's effect on endothelial injury remains unclear. The aim of the present study was to evaluate the effects and possible mechanisms of action underlying heparin treatment in lipopolysaccharide (LPS)-induced endothelial injury in vitro. TNF- $\alpha$, IL-1 $\beta$, IL- 6 and IFN- $\gamma$ levels were measured using ELISA. Cell proliferation was measured using a 5-ethynyl-2'-deoxyuridine (EdU) assay. The number of apoptotic cells and apoptotic rate were evaluated using TUNEL assays and flow cytometry, respectively. Toll-like receptor 4 (TLR4), myeloid differentiation primary response 88 (MyD88) and $\mathrm{NF}-\kappa \mathrm{B}$ (p65) gene expression was evaluated using reverse transcription-quantitative PCR, whilst TLR4, MyD88 and $\mathrm{p}-\mathrm{NF}-\kappa \mathrm{B}$ (p65) protein expression was evaluated using western blot analysis. The levels of phosphorylated $N F-\kappa B$ in the nucleus were evaluated using cellular immunofluorescence. Compared with those in the normal control group, TNF- $\alpha$, IL-1 $\beta$, IL-6 and IFN- $\gamma$ levels were significantly increased in the LPS group $(\mathrm{P}<0.001)$. In addition, 5-ethynyl-2'-deoxyuridine (EdU)-positive cells were significantly increased and apoptosis was significantly decreased $(\mathrm{P}<0.001)$. TLR4, MyD88 and NF- $\mathrm{NB}$ (p65) expression was also significantly increased $(\mathrm{P}<0.001)$. Compared with those in the LPS group, following heparin treatment, TNF- $\alpha$, IL-1 $\beta$, IL- 6 and IFN- $\gamma$ levels were significantly decreased $(\mathrm{P}<0.05)$, whilst the number of EdU-positive cells was significantly increased and the level of apoptosis was significantly decreased $(\mathrm{P}<0.05)$. TLR4, MyD88 and NF- $\mathrm{NB}$ (p65) expression was also significantly decreased
\end{abstract}

Correspondence to: Dr Qingshan Ye, Department of Anesthesiology, People's Hospital of Ningxia Hui Autonomous Region, 301 Zhengyuan North Street, Yinchuan, Ningxia 750002, P.R. China

E-mail: yeqingshan0914@21cn.com

Keywords: heparin, endothelial injury, apoptosis, toll-like receptor 4/ myeloid differentiation primary response $88 / \mathrm{NF}-\kappa \mathrm{B}$ (p65) by heparin in a dose-dependent manner $(\mathrm{P}<0.001)$. Small interfering RNA-TLR4 transfection exerted similar effects to those mediated by heparin in alleviating endothelial injury. In conclusion, heparin suppressed LPS-induced endothelial injury through the regulation of TLR4/MyD88/NF- $\mathrm{KB}(\mathrm{p} 65)$ signaling in vitro.

\section{Introduction}

The vascular endothelium is considered to be crucial for maintaining physiological balance in the vascular system and is therefore regarded as the 'guardian' of vascular health (1). Endothelial dysfunction has been implicated in the pathogenesis of cardiovascular diseases (2). Functional changes in the endothelial cells and vascular system have been reported to serve an important role in the pathology of a range of diseases, including peripheral vascular disease, stroke, heart disease, diabetes mellitus, insulin resistance, chronic renal failure, tumor growth and metastasis, venous thrombosis and severe viral infections (3). Endothelial cells can synthesize and subsequently release a number of factors that are involved in regulating local permeability, vascular tension, smooth muscle cell proliferation and migration, inflammatory response and platelet function (4). Perturbation of the tightly regulated balance in the vasculature can result in the development of atherosclerotic lesions of varying severity (5). Therefore, approaches aimed at improving vascular endothelial function can reduce the risk of or alleviate cardiovascular disease (6). Nitric oxide (NO) is a key signaling molecule that is produced by vascular endothelial cells and serves an important role in maintaining vascular tone and antioxidant stress (7). In addition, other factors can also activate endothelial cells, including lipopolysaccharide (LPS), IL-1 and TNF- $\alpha$, all of which are dependent on the activation status of the NF- $\kappa \mathrm{B}$ pathway (8). Endothelial cell activation can result in the reduction in NO bioavailability (6), which in turn weakens the regulatory functions of the endothelium over vascular tone, proliferation, thrombosis, immunocyte reaction and barrier activity (7). In this regard, this reduction in NO production or bioavailability can be regarded to be a predictor of endothelial dysfunction (9). 
Heparin is a high-concentration sulfated glycosaminoglycan with strong acidity and a molecular weight of $1,200-40,000 \mathrm{kDa}(10)$. It is a natural anticoagulant in mammalian mast cells and neutrophils (11) and promotes transcription and release of placental growth factor from endothelial cells (12). As an anticoagulant, heparin has anti-inflammatory properties (13). However, to the best of our knowledge, the effect of heparin in LPS-induced endothelial injury remains unclear. Therefore, in the present study, experiments were performed to investigate the possible effects and related mechanism of heparin on vascular inflammation-induced endothelial injury.

\section{Materials and methods}

\section{Materials}

Reagents. Heparin solution, with a molecular weight of 1,200 Da, was obtained from Changzhou Qianhong Biochemical Pharmaceutical Co., Ltd. High-glucose DMEM, newborn calf serum (NBCS) and trypsin was purchased from Thermo Fisher Scientific, Inc. LPS was obtained from EMD Millipore. The ECL detection kit, PI and DAPI staining solutions were acquired from Beyotime Institute of Biotechnology. GAPDH (cat. no. ab8245), toll-like receptor 4 (TLR4; cat. no. ab13556), myeloid differentiation primary response 88 (MyD88; cat. no. ab107585), p-NF-кB (p65; cat. ab222494) and phosphorylated (p)-NF- $\kappa \mathrm{B}$ (p65; cat. no. ab183559) primary antibodies were purchased from Abcam. Goat anti-rabbit IgG HRP-conjugated (cat. no. 70748; Cell Signaling Technology, Inc.) and FITC-labeled secondary antibodies (cat. no. A10530; ThermoFisher Scientific, Inc.) were obtained from Bioworld Technology, Inc. Small interfering RNA (si)-TLR4 (sense, 5'-GGGCUUAGAACAACUAGAATT-3'; antisense, 5'-UUC UAGUUGUUCUAAGCCCTT-3') and si-negative control (si-NC; sense, 5'-UUCUCCGAACGUGUCACGUTT-3'; antisense, 5'-ACGUGACACGUUCGGAGAATT-3') construction was performed by Nanjing KeyGen Biotech. Co. Ltd.

Equipment. The inverted fluorescence microscope was obtained from Olympus Corporation and the chemiluminescence imaging system was from Bio-Rad Laboratories, Inc.

Cell lines. HUVECs were purchased from The Cell Bank of Type Culture Collection of the Chinese Academy of Sciences.

\section{Methods}

Cell culture. HUVECs were cultured in high-glucose DMEM supplemented with $15 \%$ NBCS in a cell incubator at $37^{\circ} \mathrm{C}$ with $5 \% \mathrm{CO}_{2}$, for a passage cycle of 2-3 days.

Construction of an inflammatory injury model of HUVECs. HUVECs were inoculated into a six-well plate at a concentration of $2 \times 10^{5}$ cells $/ \mathrm{ml}$. After the cells reached $70-80 \%$ confluence, they were starved in DMEM for $12 \mathrm{~h}$. A cell model of endothelial cell inflammatory injury was established using LPS $(100 \mu \mathrm{g} / \mathrm{ml})$ for $6 \mathrm{~h}(7)$.

Cell transfection. si-TLR4 (the negative control used was si-NC) was constructed and transfected into HUVECs using Lipofectamine ${ }^{\circledR} 2000$ (Invitrogen; Thermo Fisher Scientific, Inc.) at a final concentration of $50 \mathrm{nmol} / \mathrm{l}$ of the transfection with $10 \mathrm{nM}$ si-TLR4 or si-NC. Following $6 \mathrm{~h}$ of transfection at room temperature, the DMEM medium containing $10 \%$ FBS (Sigma-Aldrich; Merck KGaA) was replaced, followed by continuous culture for $48 \mathrm{~h}$ at room temperature. The transfected cells were then collected before the transfection efficiency was evaluated using reverse transcription-quantitative PCR (RT-qPCR).

Cell grouping. HUVECs were divided into the following groups: i) Negative control(NC; cultured with DMEM medium); ii) LPS (intervention with 1,000 $\mu \mathrm{g} / \mathrm{l} \mathrm{LPS}$ ); iii) LPS + Low (induction with 1,000 $\mu \mathrm{g} / \mathrm{l} \mathrm{LPS}$ and intervention with $10 \mathrm{U} / 1$ heparin); iv) LPS + Middle (induction with 1,000 $\mu \mathrm{g} / 1 \mathrm{LPS}$ and intervention with $20 \mathrm{U} / 1$ heparin); v) LPS + High (induction with 1,000 $\mu \mathrm{g} / 1 \mathrm{LPS}$ and intervention with $100 \mathrm{U} / 1$ heparin); vi) si-TLR4 (transfection with si-TLR4 and induction with $1,000 \mu \mathrm{g} / 1 \mathrm{LPS}$ ); vii) heparin (induction with 1,000 $\mu \mathrm{g} / 1 \mathrm{LPS}$ and intervention with $100 \mathrm{U} / 1$ heparin which was the most effective concentration of heparin; heparin and LPS + High were similar in treatment); and viii) heparin + si-TLR4 (transfection with si-TLR4, induction with 1,000 $\mu \mathrm{g} / \mathrm{l} \mathrm{LPS}$ and intervention with $100 \mathrm{U} / 1$ heparin). Following $48 \mathrm{~h}$ at room temperature of the corresponding treatments (heparin and LPS were delivered together at the same time), cells from each group were used for subsequent experiments.

ELISA. TNF- $\alpha$ (cat. no. KGEHC103 $\alpha-1$ ), IL-1 $\beta$ (cat. no. KGEHC002b-1), IL-6 (cat. no. KGEHC007-1) and IFN- $\gamma$ (cat. no. KGERC101g-1) detection kits were purchased from Nanjing KeyGen Biotech, Co., Ltd. Following centrifugation of the cell culture medium in each group at 3,000 $\mathrm{x}$ g for $5 \mathrm{~min}$ at $4^{\circ} \mathrm{C}$, the supernatant was collected for subsequent measurements of the concentration of the inflammatory factors, according to the manufacturer's protocols in each kit.

5-Ethynyl-2'-deoxyuridine (EdU) staining. HUVECs in the logarithmic growth phase were seeded into a 24-well plate at a density of $5 \times 10^{4}$ cells/well. Cells were incubated with DMEM medium and then treated for $48 \mathrm{~h}$ at room temperature, according to the treatment protocol of each group. Next, $10 \mu \mathrm{mol} / 1 \mathrm{EdU}$ reagent was added to the cells and incubated for $2 \mathrm{~h}$ at room temperature, according to the protocol of the EdU fluorescence staining cell proliferation kit (cat. no. KGA331-1000; Nanjing KeyGen Biotech, Co., Ltd.). The EdU solution was removed by washing with PBS, without DNA penetration and the cells were fixed with $4 \%$ paraformaldehyde for $30 \mathrm{~min}$ at room temperature. After washing the fixation solution away with PBS, Apollo staining solution (part of Keygen EdU staining kit) was added and incubated in the dark at room temperature for $30 \mathrm{~min}$. After the staining solution was washed off with PBS, $10 \mu \mathrm{mol} / 1$ DAPI (per well) was used to stain the nucleus for $5 \mathrm{~min}$ at room temperature. Fluorescence images of five random fields of view per well were obtained using an IX73 fluorescence microscope (Olympus Corporation; magnification, x200) and EdU-positive cells were counted using ImageJ software v1.8.0 (National Institutes of Health).

Cell apoptosis detection. After $48 \mathrm{~h}$ at room temperature of corresponding treatments, HUVECs $\left(1 \times 10^{5}\right.$ cells $\left./ \mathrm{ml}\right)$ in each group were digested and collected, followed by incubation with $5 \mu \mathrm{l}$ Annexin V-FITC for $10 \mathrm{~min}$ at room temperature and $5 \mu \mathrm{l}$ PI (cat. no. KGAV113; Nanjing KeyGen Biotech, Co., Ltd.) for $10 \mathrm{~min}$ at room temperature in the dark. Apoptotic cells were then analyzed using flow cytometry. The analysis was performed using a BD FACSAria ${ }^{\mathrm{TM}}$ II flow cytometer (Becton-Dickinson and Company), and the data were analyzed 
using CellQuest Pro software (version 5.1; Becton-Dickinson and Company).

TUNEL assay. Cells were treated according to the protocols of the Fluorometric TUNEL System (cat. no. KGA7071; Nanjing KeyGen Biotech, Co., Ltd.) after corresponding treatment of HUVECs in each group for $48 \mathrm{~h}$ at room temperature. Cells were seeded on coverslips, washed three times in PBS for $5 \mathrm{~min}$ each, fixed in $4 \%$ formaldehyde for $20 \mathrm{~min}$ at room temperature and incubated in $70 \%$ ethanol at $-20^{\circ} \mathrm{C}$ for $30 \mathrm{~min}$. The coverslips were washed a further three times and the cells were permeabilized. The permeabilization was performed in $0.1 \%$ Triton $\mathrm{X}-100 / 0.1 \%$ sodium citrate at room temperature for $10 \mathrm{~min}$. After three 5-min washes in PBS, the cells were incubated with $3 \% \mathrm{H}_{2} \mathrm{O}_{2}$ at room temperature for $10 \mathrm{~min}$. After another three 5-min washes in PBS, the cells were incubated with TdT enzyme at $37^{\circ} \mathrm{C}$ for $90 \mathrm{~min}$, which was protected from light. After two 2-min washes in PBS, the nuclei were stained with Hoechst 33258 at room temperature for $20 \mathrm{~min}$ in the dark. The cells were finally washed in the dark three times in PBS containing 0.5\% Tween-20 for 2 min each and mounted in glycerol. Next, cells were observed under a fluorescence microscope and images were captured (five fields; magnification, $\mathrm{x} 200)$.

$R T-q P C R$. After $48 \mathrm{~h}$ of treatment at room temperature, HUVECs in each group were collected and total RNA was extracted using an RNAiso Plus kit (Takara Bio, Inc.). Next, cDNA synthesis was performed with a PrimeScript ${ }^{\mathrm{TM}}$ RT kit (Takara Bio, Inc.). The following thermocycling conditions were used: Initial denaturation at $95^{\circ} \mathrm{C}$ for $30 \mathrm{sec}$, then $55^{\circ} \mathrm{C}$ for $30 \mathrm{sec}$ and $72^{\circ} \mathrm{C} 30 \mathrm{sec}$. The synthesized cDNA were collected for qPCR amplification in a LightCycler 480 fluorescent PCR system (Roche Diagnostics), according to the steps of SYBR Green RT-qPCR kit (cat. no. RR086B; Takara Bio, Inc.). The reaction conditions were as follows: Pre-denaturation at $95^{\circ} \mathrm{C}$ for $15 \mathrm{~min}$, followed by 40 cycles of denaturation at $95^{\circ} \mathrm{C}$ for $10 \mathrm{sec}$, annealing at $55^{\circ} \mathrm{C}$ for $20 \mathrm{sec}$ and extension at $72^{\circ} \mathrm{C}$ for $20 \mathrm{sec}$. The genes GAPDH was used for normalization of mRNA expressions. Relative expression levels of the respective target gene were calculated according to the $2^{-\Delta \Delta \mathrm{Cq}}$ method (14). The primer sequences are shown in Table I.

Western blot (WB) analysis. HUVECs were collected following treatment in each group for $48 \mathrm{~h}$ at room temperature. The collected cells were lysed on ice with RIPA lysis buffer [10 mmol/1 Tris (pH 8.0), $150 \mathrm{mmol} / 1 \mathrm{NaCl}, 1 \%$ Nonidet P-40, 0.1\% SDS and 0.5\% deoxycholate II] for $30 \mathrm{~min}$. Cells were then centrifuged at $14,000 \mathrm{x}$ g for $30 \mathrm{~min}$ at $4^{\circ} \mathrm{C}$ and the supernatant containing the protein was obtained. Following protein quantification using a BCA assay kit, an equal amount of protein $(30 \mu \mathrm{g} /$ lane) was separated via $10 \%$ SDS-PAGE. Following electrophoresis, the proteins were transferred onto a PVDF membrane and blocked with a TBS-0.1\% Tween-20 solution containing 5\% skimmed milk. Next, the membranes were incubated with anti-TLR4 (cat. no. ab13556; 1:200), anti-MyD88 (cat. no. ab107585, 1:200), anti-p-NF-кB (p65; cat. no. ab183559; 1:200), NF-кB (p65; cat. no. ab32536; 1:200) and anti-GAPDH (cat. no. ab8245; 1:100) primary antibodies at room temperature for $2 \mathrm{~h}$. After the membranes were washed, the HRP-conjugated secondary antibody was added for subsequent incubation at a dilution of 1:4,000 at room temperature for $1 \mathrm{~h}$. ECL was used for development of
Table I. Primer sequences used for reverse transcriptionquantitative PCR.

\begin{tabular}{|c|c|}
\hline Gene & Primer sequence $\left(5^{\prime} \rightarrow 3^{\prime}\right)$ \\
\hline Toll-like & F: TGGATACGTTTCCTTATAAG \\
\hline receptor 4 & R: GAAATGGAGGCACCCCTTC \\
\hline Myeloid & F: ACCTGGCTGGTTTACACGTC \\
\hline $\begin{array}{l}\text { differentiation } \\
\text { primary } \\
\text { response } 88\end{array}$ & R: CTGCCAGAGACATTGCAGAA \\
\hline \multirow[t]{2}{*}{$\mathrm{NF}-\kappa \mathrm{B}(\mathrm{p} 65)$} & F: ATGCTTACTGGGTGCCAAAC \\
\hline & R: GGCAAGTCACTCAGCCTTTC \\
\hline \multirow[t]{2}{*}{ GAPDH } & F: AGGTCGGTGTGAACGGATTTG \\
\hline & R: TGTAGACCATGTAGTTGAGGTCA \\
\hline
\end{tabular}

F, forward; R, reverse.

the membrane to visualize the bands. ImageJ software v1.8.0 (National Institutes of Health) was used to analyze the gray values of the bands, where GAPDH was used to normalize the results.

Immunofluorescence. After $48 \mathrm{~h}$ of treatment in each group at room temperature, HUVECs were fixed with $3.5 \%$ paraformaldehyde for $10 \mathrm{~min}$ at room temperature, permeabilized with $0.2 \%$ Triton $\mathrm{X}-100$ on ice for $15 \mathrm{~min}$ and blocked with $3 \%$ BSA (Sigma-Aldrich; Merck KGaA) for 30 min. Next, a p-NF- $\mathrm{B}$ (p65; cat. ab222494; 1:200) primary antibody was added to the cells and incubated overnight at $4^{\circ} \mathrm{C}$. The next day, a FITC-labeled secondary antibody was added according to the manufacturer's instructions and incubated for $1 \mathrm{~h}$ at room temperature. Following $50 \mu \mathrm{l}$ DAPI staining for $5 \mathrm{~min}$ at room temperature, images of the stained cells were captured using a laser confocal microscope (five files; magnification, $\mathrm{x} 200$ ). This experiment was repeated three times.

Statistical analysis. SPSS 20.0 software (IBM Corp.) was used for statistical analysis. To analyze data with a normal distribution and homogeneity of variance, a one-way ANOVA was used followed by a Tukey's post hoc test for pairwise comparisons. A two-tailed hypothesis test was performed with $\alpha=0.05$. $\mathrm{P}<0.05$ was considered to indicate a statistically significant difference. The experiments were repeated three times.

\section{Results}

Effect of heparin on TNF- $\alpha, I L-1 \beta, I L-6$ and IFN- $\gamma$ levels in LPS-induced endothelial injury. Compared with those in the NC group, the levels of TNF- $\alpha$, IL- $1 \beta$, IL- 6 and IFN- $\gamma$ in the LPS group were significantly higher (all $\mathrm{P}<0.001$; Fig. 1). In the heparin groups, the levels of TNF- $\alpha$, IL-1 $\beta$, IL-6 and IFN- $\gamma$ were all significantly decreased compared with those in the LPS group (all $\mathrm{P}<0.05$; Fig. 1). In addition, there was a significant dose-dependent effect among the three heparin treatment groups (all $\mathrm{P}<0.05$; Fig. 1).

Effect of heparin on the proliferating cell count after $L P S$-induced endothelial injury. A significant reduction in 

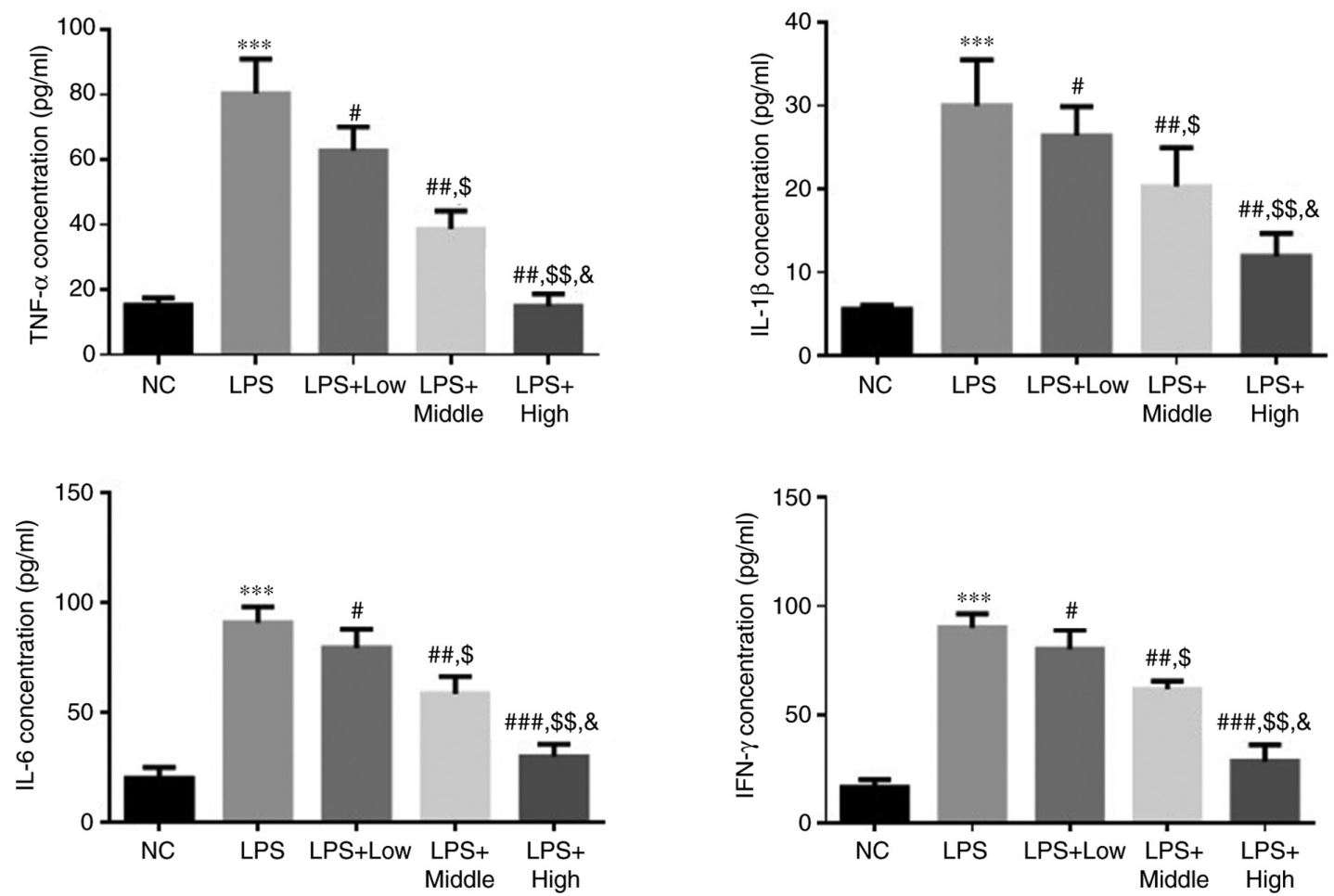

Figure 1. Effect of heparin on TNF- $\alpha$, IL-1 $\beta$, IL-6 and IFN- $\gamma$ levels in LPS-induced endothelial cell injury. ${ }^{* * *} \mathrm{P}<0.001{ }^{\text {vs. NC; }}{ }^{*} \mathrm{P}<0.05$, ${ }^{\# \#} \mathrm{P}<0.01$ and

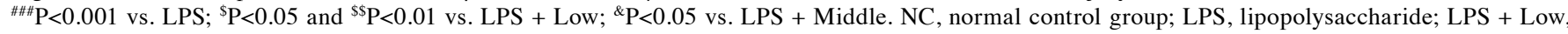
LPS-stimulated cells were treated with low-dose heparin (10 U/1); LPS + Middle, LPS-stimulated cells were treated with middle-dose heparin (20 U/1); LPS + High, LPS-stimulated cells were treated with high-dose heparin (100 U/l).
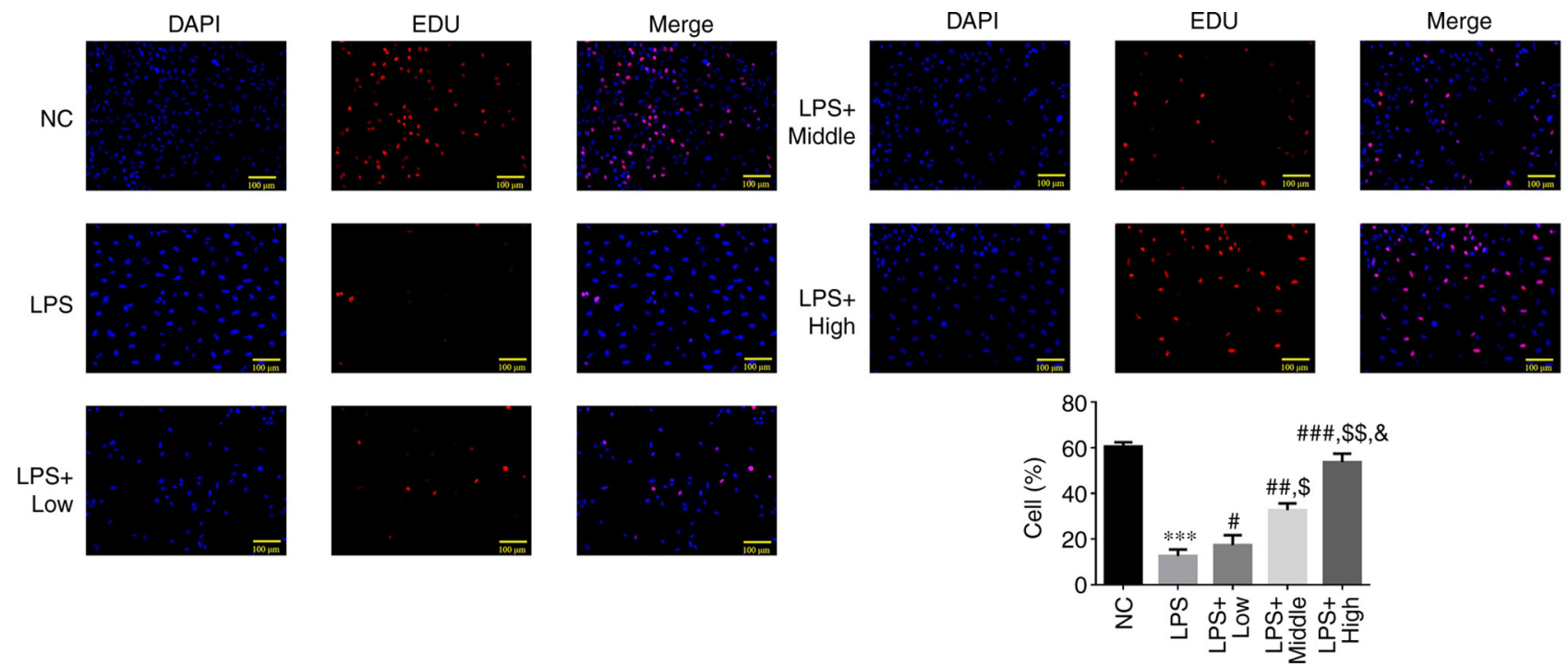

Figure 2. Effect of heparin on the number of proliferating cells after LPS-induced endothelial cell injury. ${ }^{* * *} \mathrm{P}<0.001 \mathrm{vs}$. NC; ${ }^{*} \mathrm{P}<0.05$, ${ }^{\# *} \mathrm{P}<0.01$ and

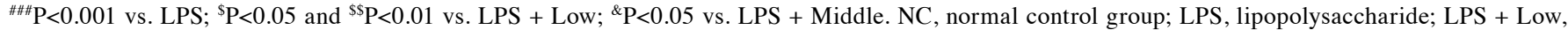
LPS-stimulated cells were treated with low-dose heparin (10 U/l); LPS + Middle, LPS-stimulated cells were treated with middle-dose heparin (20 U/l); LPS + High, LPS-stimulated cells were treated with high-dose heparin (100 U/1); EdU, 5-ethynyl-2'-deoxyuridine.

the EdU-positive cell count was observed in the LPS group compared with that in the NC group $(\mathrm{P}<0.001$; Fig. 2). By contrast, the EdU-positive cell count was significantly increased in the three heparin groups compared with that in the LPS group (P<0.05; Fig. 2), where a significant dose-dependent effect was observed among the three heparin treatment groups (all P<0.05; Fig. 2).
Flow cytometry analysis of heparin-mediated regulation of apoptosis following LPS-induced endothelial injury. According to the flow cytometry results, the apoptotic rate in the LPS group was significantly higher compared with that of the NC group ( $\mathrm{P}<0.001$; Fig. 3A). The apoptotic rate in all three of the heparin groups was significantly lower compared with that in the LPS group $(\mathrm{P}<0.05 ;$ Fig. $3 \mathrm{~A})$, with a significant 

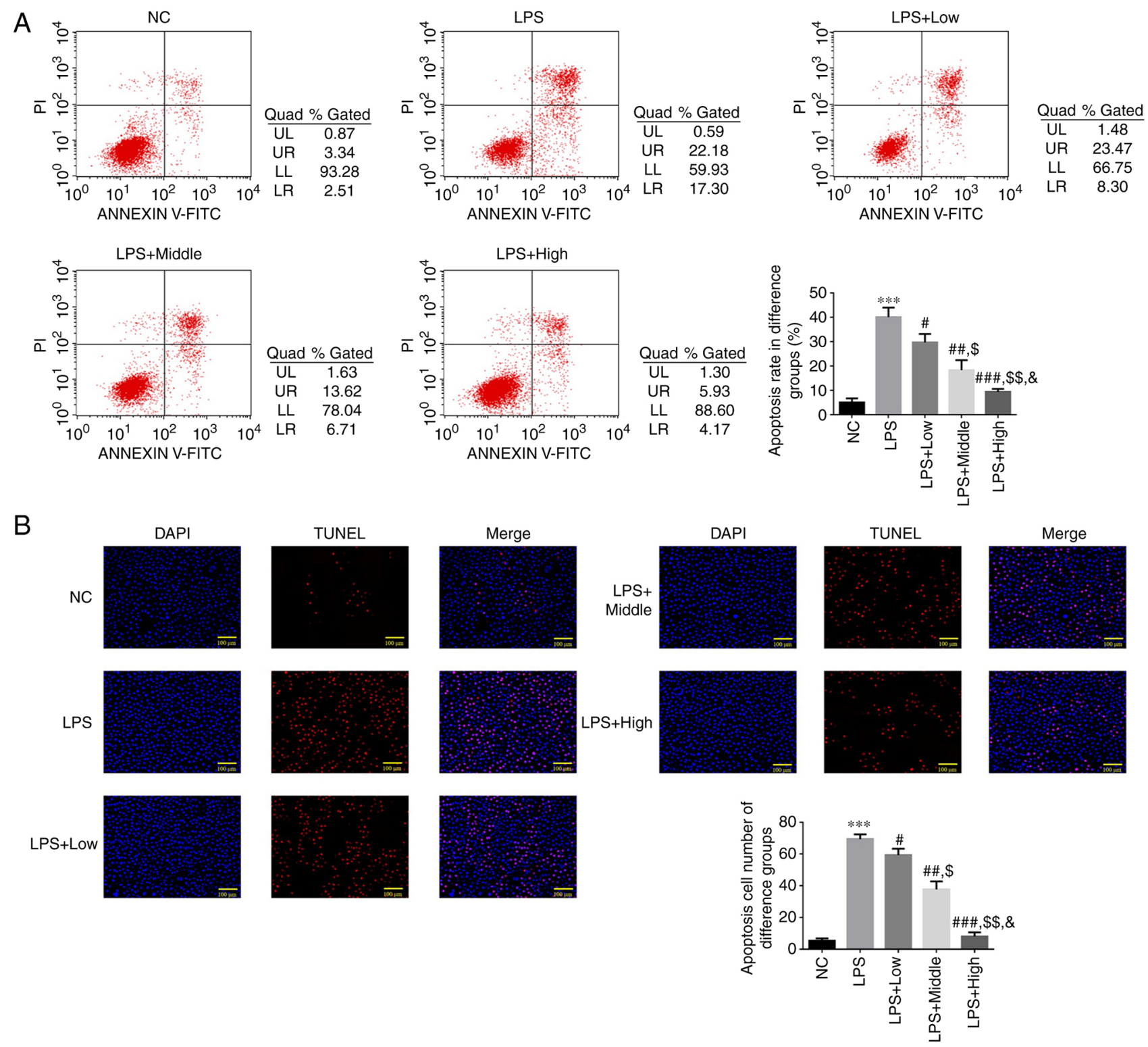

Figure 3. Effects of heparin on LPS-induced endothelial cell apoptosis. (A) Flow cytometric detection of the effects of heparin on the regulation of apoptosis in LPS-treated endothelial cells. (B) TUNEL assay detection of the effects of heparin on the regulation of apoptosis in LPS-treated endothelial cells. ${ }^{* * * *} \mathrm{P}<0.001$ vs. $\mathrm{NC}$; ${ }^{\# \mathrm{P}}<0.05$, ${ }^{\# \#} \mathrm{P}<0.01$ and ${ }^{\# \# \#} \mathrm{P}<0.001$ vs. LPS group; ${ }^{\$} \mathrm{P}<0.05$ and ${ }^{\$ \$} \mathrm{P}<0.01$ vs. $\mathrm{LPS}+\mathrm{Low} ;{ }^{\circledR} \mathrm{P}<0.05$ vs. LPS + Middle. NC, normal control group; LPS, lipopolysaccharide; LPS + Low, LPS-stimulated cells were treated with low-dose heparin (10 U/l); LPS + Middle, LPS-stimulated cells were treated with middle-dose heparin (20 U/1); LPS + High, LPS-stimulated cells were treated with high-dose heparin (100 U/l).

dose-dependent effect observed among the three heparin groups (all $\mathrm{P}<0.05$; Fig. 3A).

TUNEL detection analysis of heparin-mediated regulation of cell apoptosis following LPS-induced endothelial injury. The TUNEL assay results indicated that the LPS group exhibited a significantly increased count of TUNEL-positive cells compared with that in the $\mathrm{NC}$ group $(\mathrm{P}<0.001$; Fig. 3B). However, the number of TUNEL-positive cells in the three heparin groups was significantly decreased compared with that in the LPS group $(\mathrm{P}<0.05$; Fig. 3B), with a significant dose-dependent effect observed among the three heparin groups (all $\mathrm{P}<0.05$; Fig. 3B).

Effect of heparin on TLR4, MyD88 and NF- $\kappa B$ p65 expression. According to the RT-qPCR results, si-TLR4 significantly decreased TLR4 gene expression, as presented in Fig. S1, the LPS group exhibited significantly increased mRNA expression levels of TLR4, MyD88 and NF- $\kappa B$ (p65) compared with those in the $\mathrm{NC}$ group (all $\mathrm{P}<0.001$; Fig. 4A). However, intervention with all three doses of heparin significantly downregulated the expression levels of TLR4, MyD88 and NF- $\kappa B$ (p65) compared with those in the LPS group (all $\mathrm{P}<0.05$; Fig. $4 \mathrm{~A}$ ), with a significant dose-dependent effect observed among the three groups (all $\mathrm{P}<0.05$; Fig. 5). In addition, WB results showed that compared with those in the NC group, the protein expression levels of TLR4, MyD88 and $\mathrm{p}-\mathrm{NF}-\kappa \mathrm{B}(\mathrm{p} 65)$ were all significantly upregulated in the LPS group (all $\mathrm{P}<0.001 ;$ Fig. 4B). A significant decrease in the protein expression of TLR4, MyD88 and p-NF- $\mathrm{kB}$ (p65) was also observed in the three heparin groups compared with that in the LPS group (all P<0.05; Fig. 4B). In addition, a significant 
A

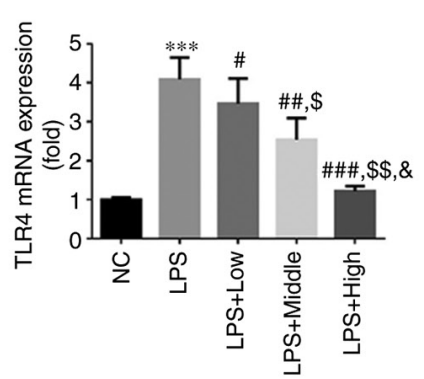

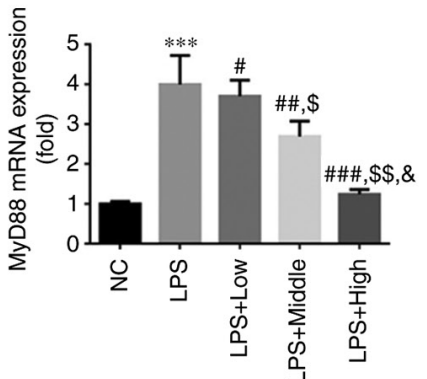

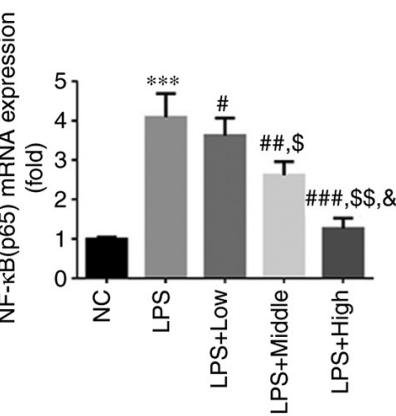

B
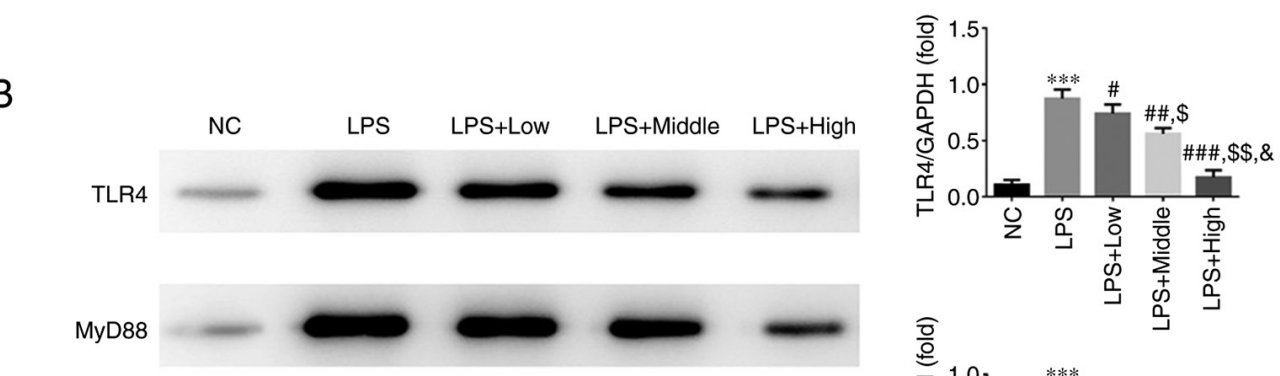

$\mathrm{p}-\mathrm{NF}-\mathrm{kB}(\mathrm{p} 65)$

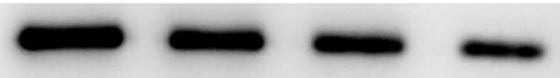

$\mathrm{NF}-\mathrm{KB}(\mathrm{p} 65)$

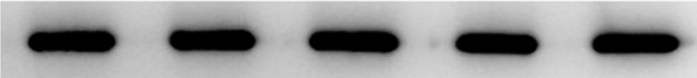

GAPDH

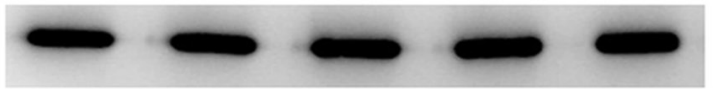

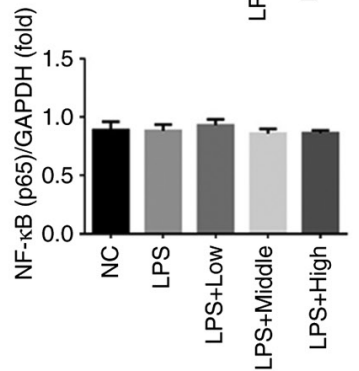
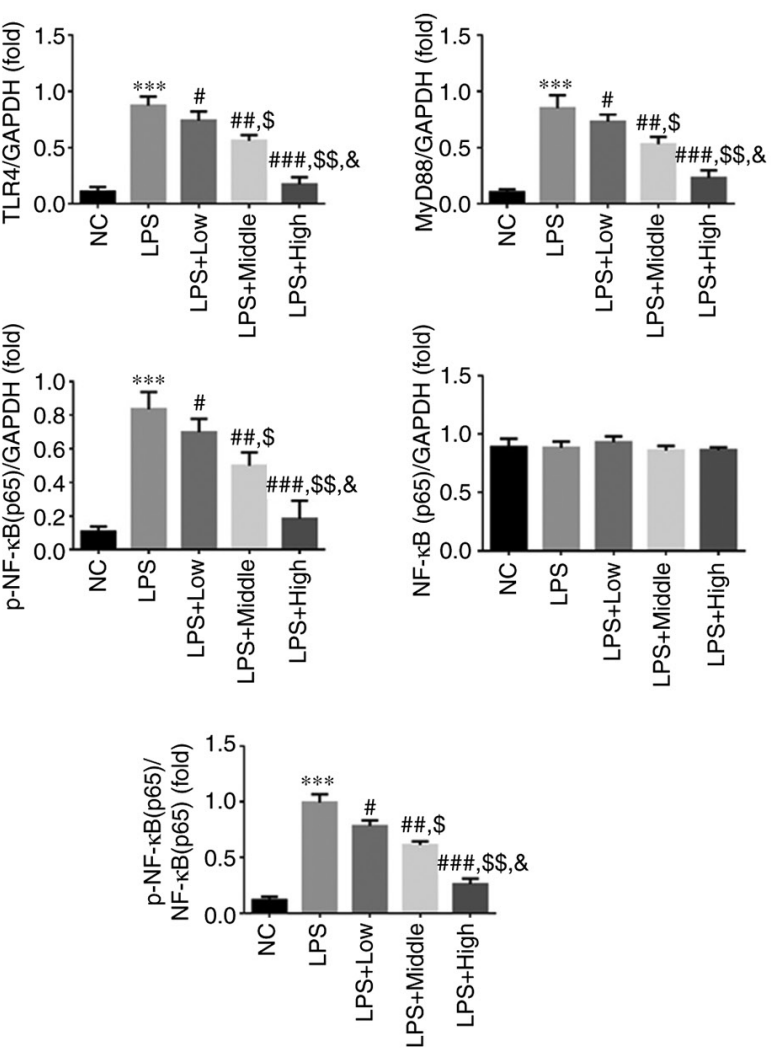

Figure 4. Effect of heparin on the expression of TLR4, myD88 and NF- $\kappa$ B p65 in endothelial cells. (A) Relative TLR4, myD88 and NF- $\kappa$ B p65 mRNA expression in the different treatment groups. (B) Relative TLR4, myD88 and NF- $\kappa \mathrm{B}$ p65 protein expression in the different treatment groups. ${ }^{*}$ P $<0.001$ vs. NC; ${ }^{\#} \mathrm{P}<0.05,{ }^{\# \#} \mathrm{P}<0.01$ and ${ }^{\# \# \#} \mathrm{P}<0.001$ vs. LPS; ${ }^{\$} \mathrm{P}<0.05$ and ${ }^{\$} \mathrm{P}<0.01$ vs. LPS + Low group; ${ }^{\circledR} \mathrm{P}<0.05$ vs. LPS + Middle. NC, normal control group; LPS, lipopolysaccharide; LPS + Low, LPS-stimulated cells were treated with low-dose heparin (10 U/1); LPS + Middle, LPS-stimulated cells were treated with middle-dose heparin (20 U/1); LPS + High, LPS-stimulated cells were treated with high-dose heparin (100 U/1); TLR4, toll-like receptor 4; myD88, myeloid differentiation primary response 88 .

dose-dependent effect was observed among the three heparin groups (all $\mathrm{P}<0.05$; Fig. 4B).

Effect of heparin on $p-N F-\kappa B$ (p65) protein translocation into the nucleus. The results of the immunofluorescence assay showed that the extent of $\mathrm{p}-\mathrm{NF}-\mathrm{\kappa B}$ (p65) protein translocation into the nucleus was significantly increased in the LPS group compared with that in the $\mathrm{NC}$ group $(\mathrm{P}<0.001$; Fig. 5). Following heparin treatment at all three doses, the amount of p-NF- $\mathrm{kB}$ (p65) protein translocated into the nucleus was significantly decreased compared with that in the LPS group (all $\mathrm{P}<0.05$; Fig. 5). In addition, a significant dose-dependent effect was observed among the three heparin groups (all $\mathrm{P}<0.05$; Fig. 5). 

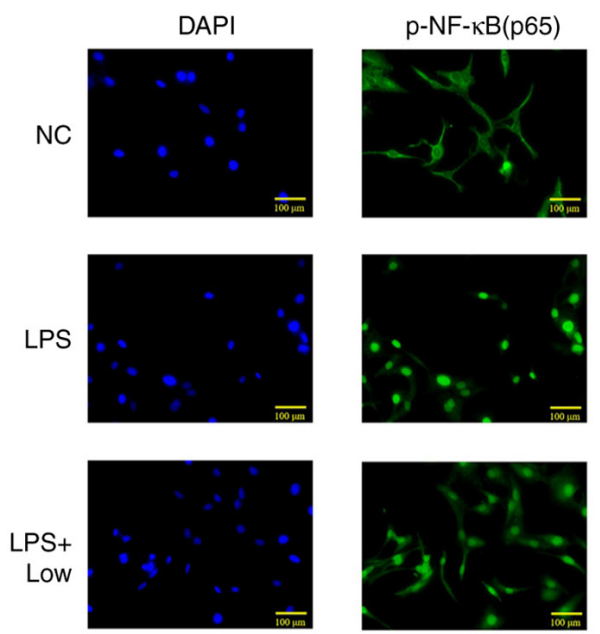
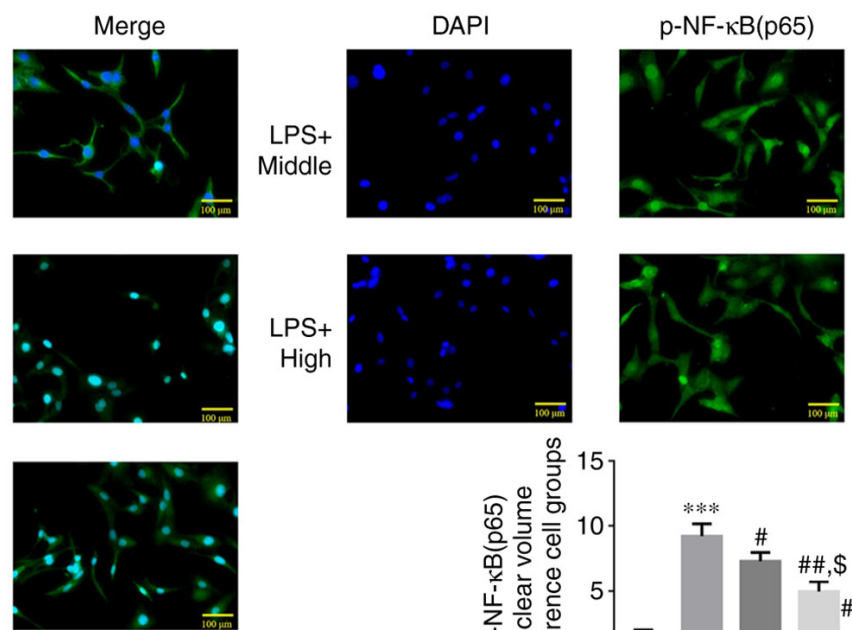
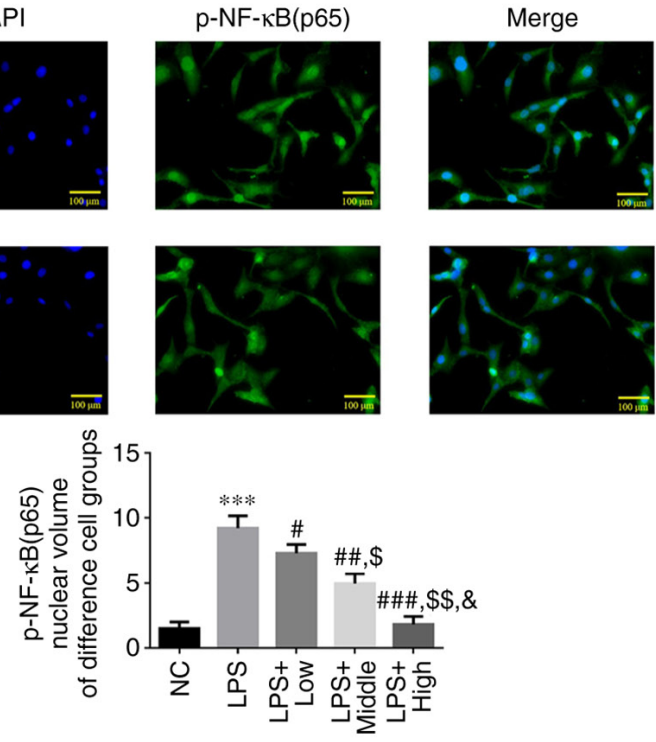

Figure 5. Effect of heparin on p-NF- $\mathrm{kB}$ (p65) protein translocation to the nucleus. ${ }^{* * *} \mathrm{P}<0.001$ vs. NC; ${ }^{\# P} \mathrm{P}<0.05$, ${ }^{\# \#} \mathrm{P}<0.01$ and ${ }^{\# \#} \mathrm{P}<0.001$ vs. LPS; ${ }^{\$} \mathrm{P}<0.05$ and ${ }^{\$ \$} \mathrm{P}<0.01$ vs. LPS + Low group; ${ }^{\&} \mathrm{P}<0.05$ vs. LPS + Middle group. NC, normal control group; LPS, lipopolysaccharide; LPS + Low, LPS-stimulated cells were treated with low-dose heparin (10 U/l); LPS + Middle, LPS-stimulated cells were treated with middle-dose heparin (20 U/l); LPS + High, LPS-stimulated cells were treated with high-dose heparin (100 U/l); p-, phosphorylated.

ELISA detection of TNF- $\alpha, I L-1 \beta, I L-6$ and IFN- $\gamma$ levels in each group. The LPS group exhibited significantly higher levels of TNF- $\alpha$, IL-1 $\beta$, IL- 6 and IFN- $\gamma$ (P<0.001; Fig. 6) compared with those in the NC group. By contrast, the si-TLR4, heparin and heparin + si-TLR4 groups all exhibited significantly lower concentrations of TNF- $\alpha$, IL- $1 \beta$, IL- 6 and IFN- $\gamma$ compared with those in the LPS group (all $\mathrm{P}<0.001$; Fig. 6). However, there was no significant difference in the levels of these factors among the si-TLR4, heparin and heparin + si-TLR4 groups (Fig. 6).

EdU detection of cell proliferation in each treatment group. A significantly decreased number of EdU-positive cells was observed in the LPS group compared with that in the NC group $(\mathrm{P}<0.001$; Fig. 7). Compared with that in the LPS group, si-TLR4, heparin and heparin + si-TLR4 groups exhibited significantly increased EdU-positive cell counts (all $\mathrm{P}<0.001$; Fig. 7). No differences could be observed in the number of proliferative cells among the si-TLR4, heparin and heparin + si-TLR4 groups (Fig. 7).

Flow cytometric detection of the cell apoptotic rate in each treatment group. The LPS group exhibited a significantly increased cell apoptotic rate compared with that in the NC group $(\mathrm{P}<0.001$; Fig. $8 \mathrm{~A})$. Compared with that in the LPS group, the apoptotic rate in the si-TLR4, heparin and heparin + si-TLR4 groups was significantly decreased (all $\mathrm{P}<0.001$; Fig. 8A). No statistical differences were observed in the apoptotic rate among the si-TLR4, heparin and heparin + si-TLR4 groups (Fig. 8A).

TUNEL detection of apoptotic cell count in each group. A significantly increased TUNEL-positive cell count was observed in the LPS group compared with that in the NC group $(\mathrm{P}<0.001$; Fig. 8B). Furthermore, the TUNEL-positive cell count was significantly decreased in the si-TLR4, heparin and heparin + si-TLR4 groups compared with that in the LPS group (all $\mathrm{P}<0.001$; Fig. 8B). No statistical differences were observed in the TUNEL-positive cell count among the si-TLR4, heparin and heparin + si-TLR4 groups (all $\mathrm{P}>0.05$; Fig. $8 \mathrm{~B}$ ).

RT-qPCR and WB measurements of TLR 4, myD 88 and NF- $\kappa B$ p65 expression. As shown in Fig. 9A, the LPS group exhibited significantly increased mRNA expression levels of TLR4, MyD88 and NF- $\mathrm{kB}$ p65 (all $\mathrm{P}<0.001)$ compared with those in the NC group. Furthermore, when compared with those in the LPS group, significantly decreased mRNA expression levels of TLR4, MyD88 and NF-kB p65 were observed in the si-TLR4, heparin and heparin + si-TLR4 groups (all $\mathrm{P}<0.001$ ). As shown in Fig. 9B, the protein expression levels of TLR4, MyD88 and NF- $\mathrm{kB}$ p65 were significantly increased in the LPS group compared with those in the NC group (all $\mathrm{P}<0.001$ ). In addition, the si-TLR4, heparin and heparin + si-TLR4 groups all exhibited significantly lower protein expression levels of TLR4, MyD88 and NF- $\kappa B$ (p65) compared with those in the LPS group (all $\mathrm{P}<0.001$ ). No significant differences were observed in the gene and protein expression levels of TLR4, MyD88 and NF- $\mathrm{kB}$ p65 among the si-TLR4, heparin and heparin + si-TLR4 groups (Fig. 9).

Immunofluorescence analysis of $p-N F-\kappa B$ p 65 protein translocation into the nucleus. Compared with that in the $\mathrm{NC}$ group, the degree of $\mathrm{p}-\mathrm{NF}-\mathrm{\kappa B}$ (p65) protein translocation into the nucleus was increased in the LPS group (all $\mathrm{P}<0.001$; Fig. 10). However, compared with that in the LPS group, $\mathrm{p}-\mathrm{NF}-\mathrm{\kappa B}$ p 65 protein translocation into the nucleus was decreased in the si-TLR4, heparin and heparin + si-TLR4 groups (all $\mathrm{P}<0.001)$. No statistical differences were observed in $\mathrm{p}-\mathrm{NF}-\kappa \mathrm{B} \mathrm{p} 65$ protein translocation into the nucleus among the si-TLR4, heparin and heparin + si-TLR4 groups (Fig. 10). 

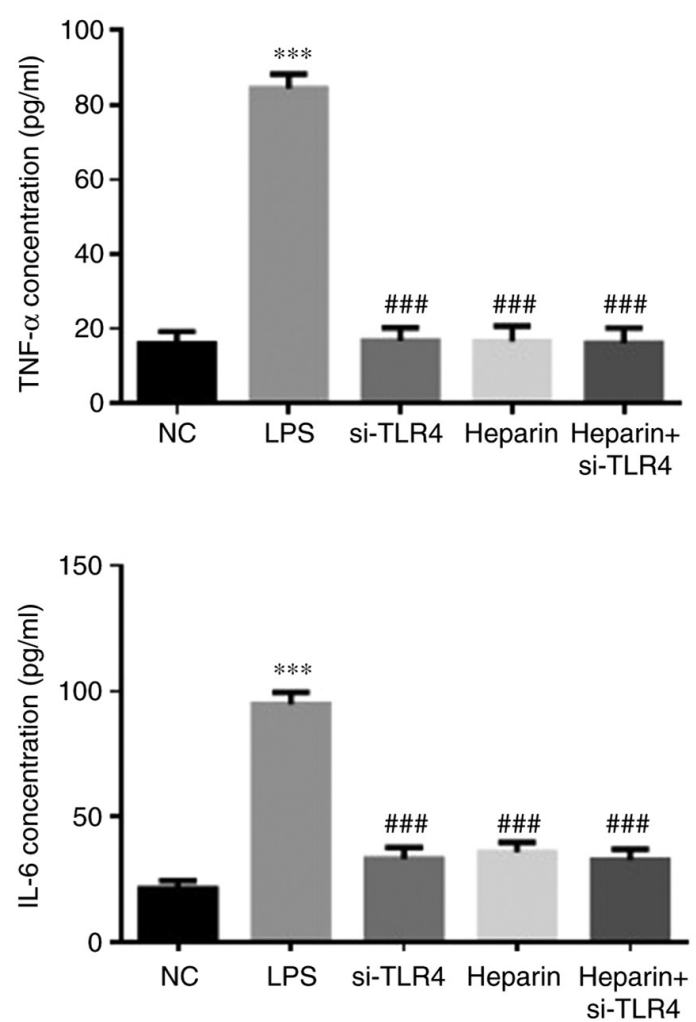

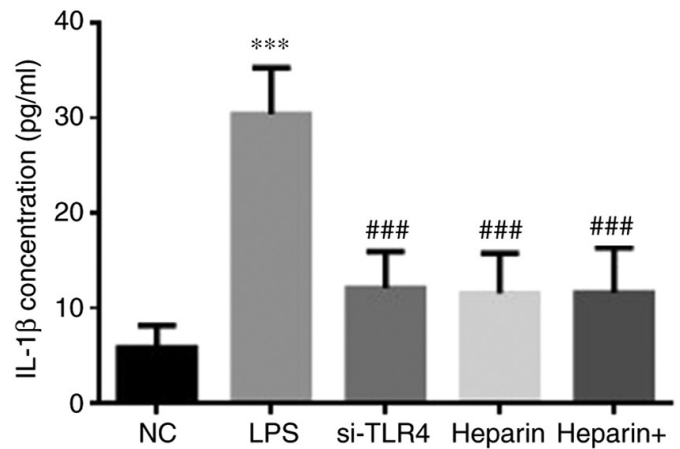

si-TLR4

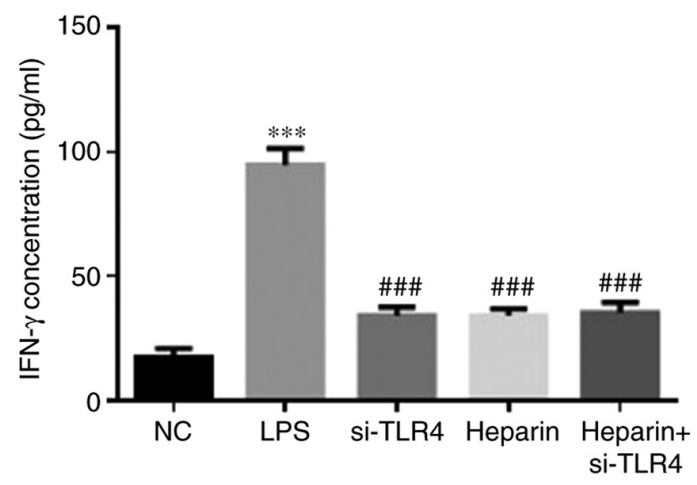

Figure 6. ELISA detection of the concentrations of TNF- $\alpha$, IL-1 $\beta$, IL-6 and IFN- $\gamma$ in each group. ${ }^{* * * *} \mathrm{P}<0.001$ vs. NC; \#\#" $\mathrm{P}<0.001$ vs. LPS. NC, normal control group; TLR4, toll-like receptor 4; LPS, lipopolysaccharide; si, small interfering RNA; si-TLR4, LPS-stimulated cells were transfected with si-TLR4; heparin, LPS-stimulated cells were treated with $100 \mathrm{U} / 1$ heparin; heparin + si-TLR4,LPS-stimulated cells were transfected with si-TLR4 and treated with $100 \mathrm{U} / 1$ heparin.
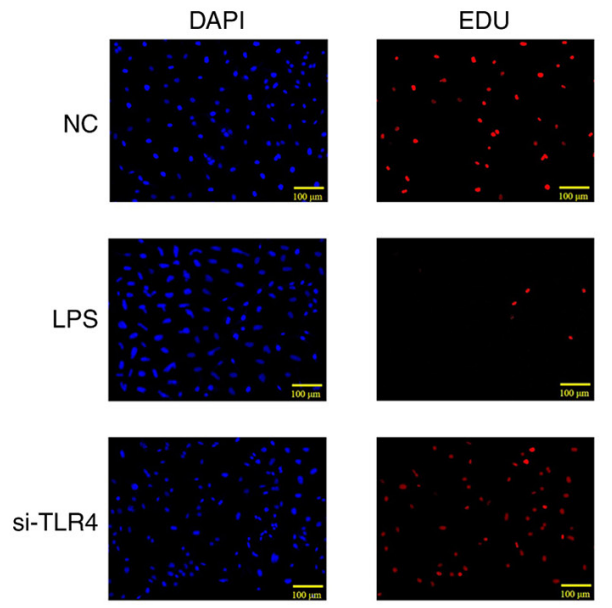
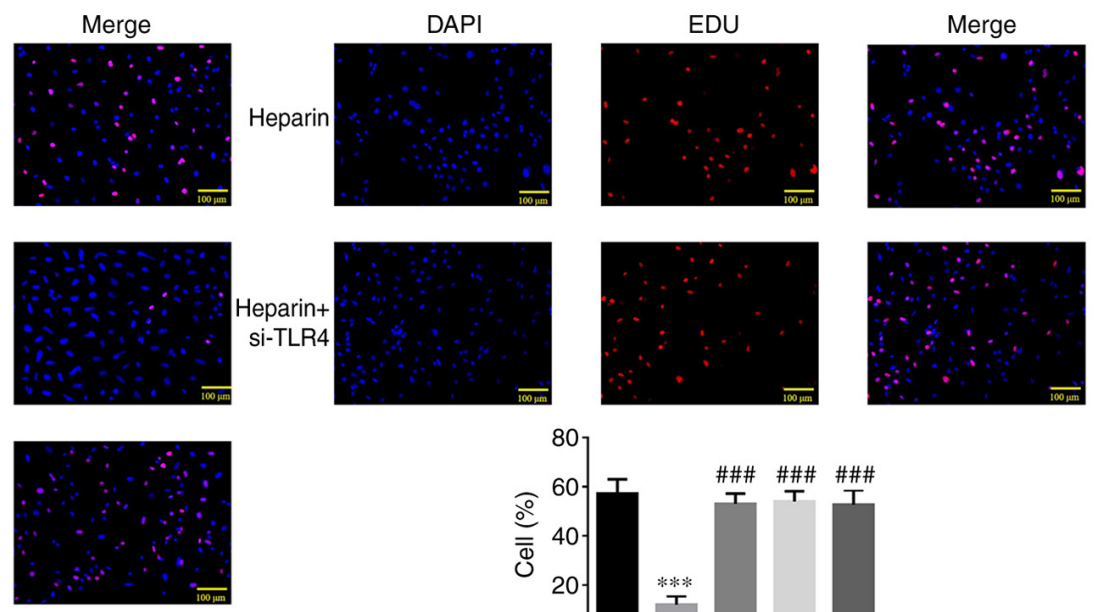

Figure 7. EdU detection of cell proliferation in each treatment group. ${ }^{* * *} \mathrm{P}<0.001$ vs. NC; ${ }^{\# \#} \mathrm{P}<0.001$ vs. LPS. EdU, 5 -ethynyl-2'-deoxyuridine; NC, normal control group; TLR4, toll-like receptor 4; LPS, lipopolysaccharide; si, small interfering RNA; si-TLR4, LPS-stimulated cells were transfected with si-TLR4; heparin, LPS-stimulated cells were treated with $100 \mathrm{U} / 1$ heparin; heparin + si-TLR4,LPS-stimulated cells were transfected with si-TLR4 and treated with $100 \mathrm{U} / 1$ heparin.

\section{Discussion}

LPS has been identified to be the main component of the cell wall of gram-negative bacteria (15). After being transported by LPS binding protein (LBP), LPS binds to CD14 expressed on various cytoplasmic membranes (16). After binding with the LPS-LBP complex, CD14 activates the NF- $\mathrm{kB}$ signaling pathway through TLR4 (17). The resulting signaling cascade activated can then promote the release of inflammatory cytokines, including IL- 6 and TNF- $\alpha(13,18,19)$.

TLRs are key components of the innate immune system (20). Following activation, TLRs relay the inflammatory signaling information through a MyD88-dependent pathway to activate the expression and secretion of inflammatory factors, resulting 
A
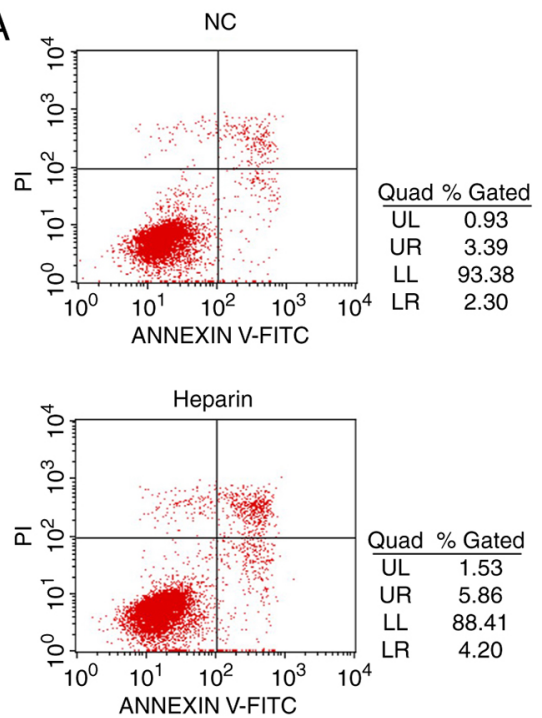

B

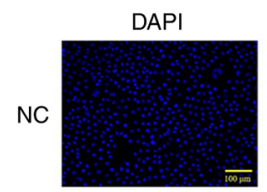

LPS
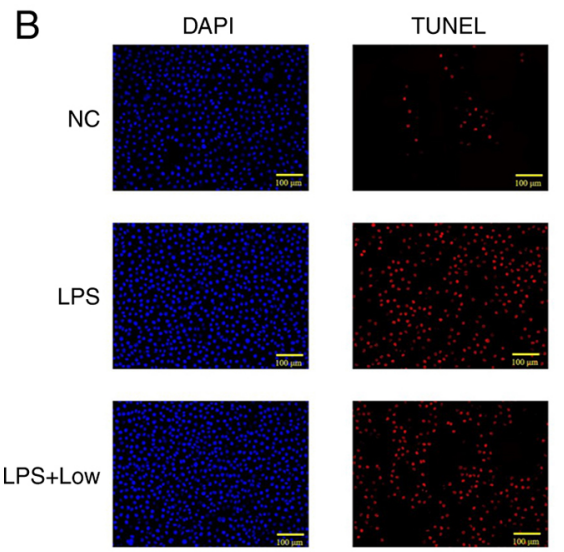
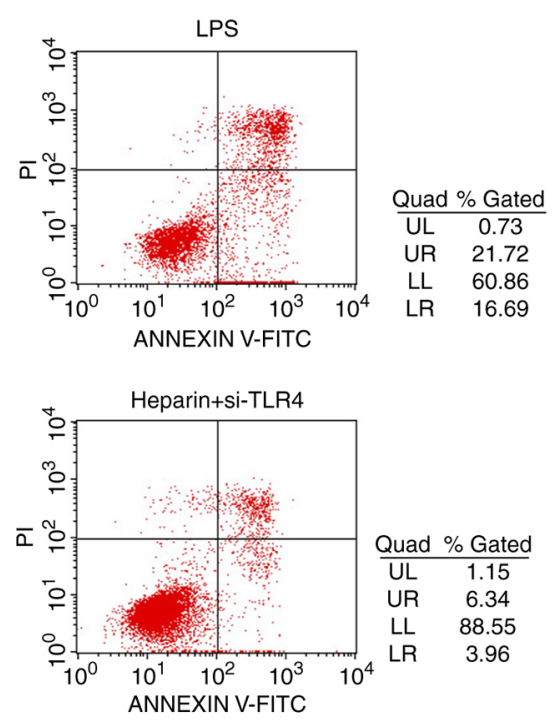
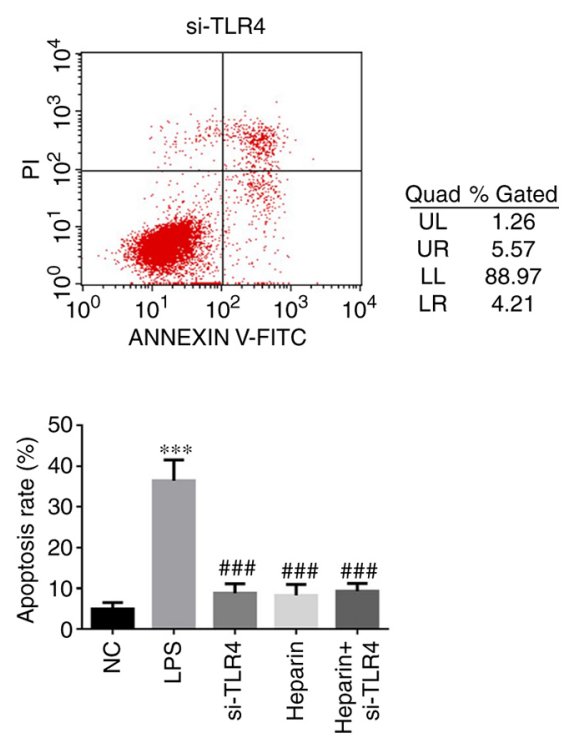
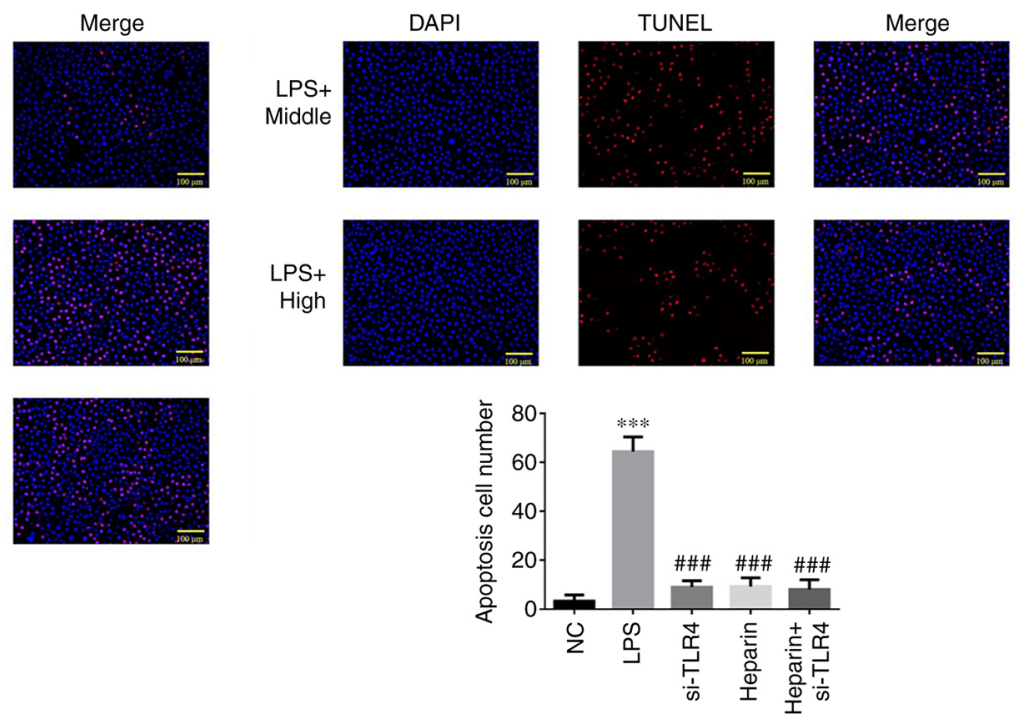

Figure 8. Cell apoptosis measurements using flow cytometric and TUNEL assays. (A) Flow cytometric detection of the cell apoptotic rate in each treatment group.

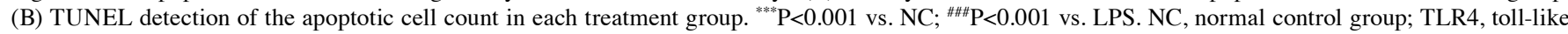
receptor 4; LPS, lipopolysaccharide; si, small interfering RNA; si-TLR4, LPS-stimulated cells were transfected with si-TLR4; heparin, LPS-stimulated cells were treated with $100 \mathrm{U} / 1$ heparin; heparin + si-TLR4, LPS-stimulated cells were transfected with si-TLR4 and treated with 100 U/1 heparin.

in inflammatory lesions (21-23). Downstream, NF- $\kappa$ B (p65) is an important inflammatory regulator (24). As a transcription factor, it can activate the expression of a number of inflammatory cytokines, including TNF- $\alpha$, IL- $1 \beta$, IFN- $\gamma$ and IL-6 (25-27). The expression of inflammatory factors induced by $\mathrm{NF}-\kappa \mathrm{B}$ p 65 can lead to potentiation of $\mathrm{NF}-\kappa \mathrm{B}$ activation by positive feedback, which is mediated by the continuous translocation of p-NF- $\mathrm{B}$ p 65 into the nucleus, aggravating inflammatory injury (28). Consequently, the TLR4/MyD88/NF- $\mathrm{B}$ p65 signaling pathway serves a key role in the inflammatory response.

Vascular endothelial cells at the inflammatory site can serve a dual role, either as a participant or a regulator in the inflammatory process (29). Incalza et al (30) found that long-term or repeated exposure to risk factors of cardiovascular diseases can damage the endogenous anti-inflammatory system within endothelial cells. Consequently, the endothelium can lose not only its function, but endothelial cells can also detach from the endothelium and enter the circulatory system, which can induce an inflammatory reaction (31). Therefore, repairing endothelial cell injury can serve an important role in preserving vascular function (32).

A previous study (32) reported that heparin had anti-inflammatory effects. In the present study, heparin exerted an inhibitory effect on LPS-induced HUVEC apoptosis, secretion of the inflammatory cytokines TNF- $\alpha$, IL-1 $\beta$, IL- 6 and IFN- $\gamma$, in addition to reducing the protein levels of TLR4, MyD88 and p-NF- $\mathrm{B}$ p65. However, no significant enhancements were observed when heparin and TLR4 knockdown were combined. Therefore, it was concluded that heparin may serve an anti-inflammatory and protective role in vascular endothelial injury by downregulating the TLR4/MyD88/NF- $\mathrm{B}$ (p65) signaling pathway.

In the present study, in vitro experiments were conducted, where the results showed that heparin may exert a protective effect on LPS-induced acute vascular endothelial injury. The 

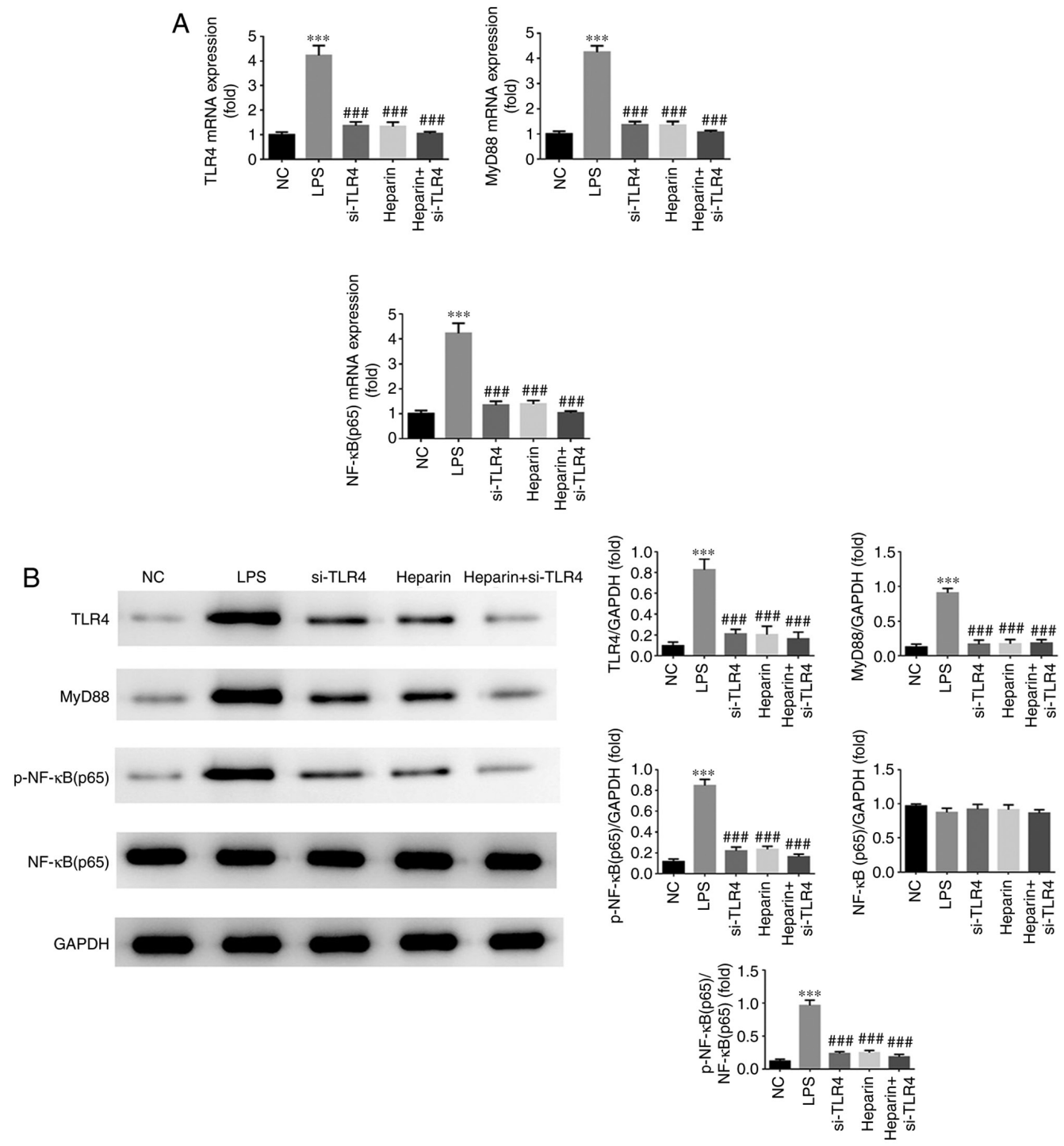

Figure 9. Reverse transcription-quantitative PCR and western blot detection of TLR4, myD88 and NF- $\mathrm{kB}$ p65 gene and protein expression. (A) Relative TLR4,

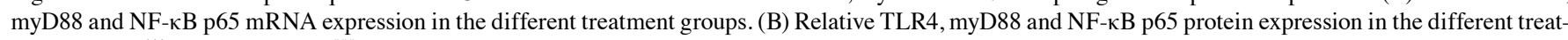
ment groups. ${ }^{* * *} \mathrm{P}<0.001$ vs. NC; ${ }^{\# \#} \mathrm{P}<0.001$ vs. LPS. NC, normal control group; TLR4, toll-like receptor 4; LPS, lipopolysaccharide; si, small interfering RNA; myD88, myeloid differentiation primary response 88; p-, phosphorylated; si-TLR4, LPS-stimulated cells were transfected with si-TLR4; heparin, LPS-stimulated cells were treated with $100 \mathrm{U} / 1$ heparin; heparin + si-TLR4, LPS-stimulated cells were transfected with si-TLR4 and treated with $100 \mathrm{U} / 1$ heparin.
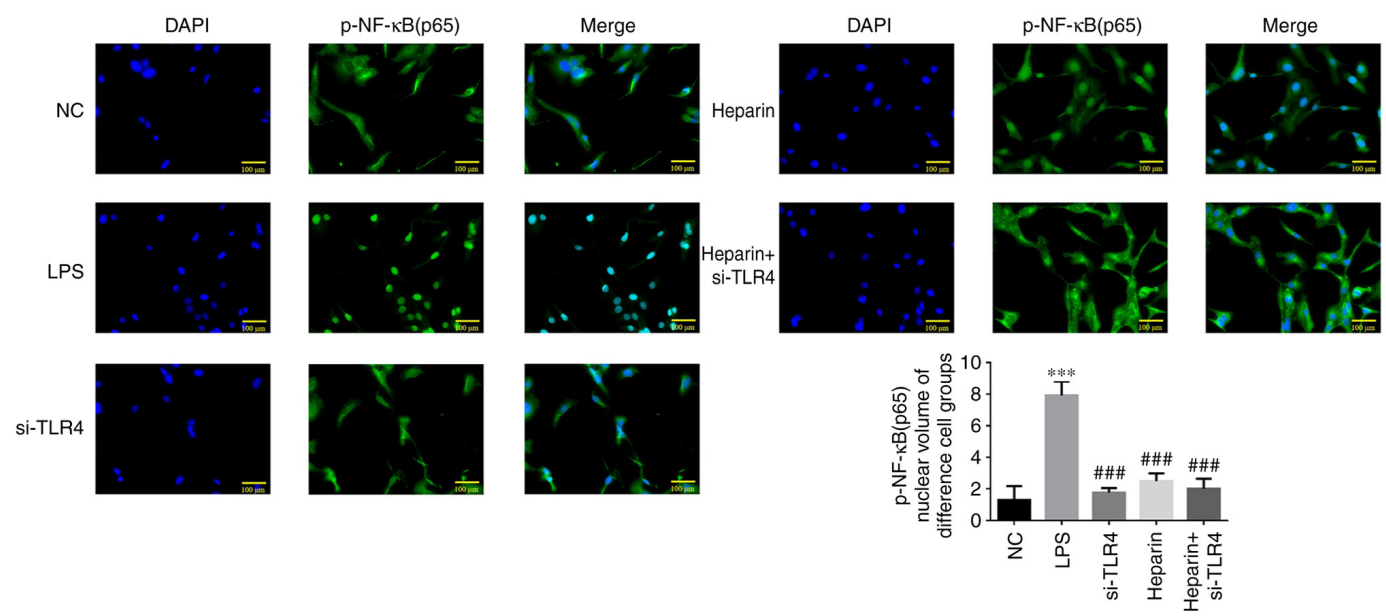

Figure 10. Immunofluorescence analysis for p-NF- $\mathrm{KB}$ (p65) protein translocation to the nucleus. ${ }^{* * *} \mathrm{P}<0.001 \mathrm{vs}$. NC; ${ }^{\# \# \#} \mathrm{P}<0.001$ vs. LPS. NC, normal control group; LPS, cells were treated with LPS; p-, phosphorylated; si, small interfering RNA; TLR4, toll-like receptor 4; si-TLR4, LPS-stimulated cells were transfected with si-TLR4; heparin, LPS-stimulated cells were treated with $100 \mathrm{U} / 1$ heparin; heparin + si-TLR4, LPS-stimulated cells were transfected with si-TLR4 and treated with $100 \mathrm{U} / 1$ heparin. 
specific mechanism can be explained by its role in reducing the inflammatory reaction and inhibiting the TLR4/MyD88/NF-кB (p65) signaling pathway. The findings of the present study may provide a foundation for further investigations into the protective effect of heparin on the cardiovascular system.

\section{Acknowledgements}

Not applicable.

\section{Funding}

This study was supported by the National Natural Science Foundation of China (grant no. 81760339), Ningxia Natural Science Foundation of China (grant no. 2020AAC03331) and the Fourth Batch of Ningxia Youth Talents Supporting Program (grant no. TJGC2019087).

\section{Availability of data and materials}

The datasets used and/or analyzed during the current study are available from the corresponding author on reasonable request.

\section{Authors' contributions}

WL and QY designed the study. WL, YW and YL performed the ELISA, flow cytometry and TUNEL experiments, ZW, $\mathrm{XZ}$ and $\mathrm{KH}$ performed the rest of the experiments. WL, YW and $\mathrm{XZ}$ wrote the manuscript. All authors read and approved the final version of the manuscript. WL and QY confirm the authenticity of all the raw data.

\section{Ethics approval and consent to participate}

Not applicable.

\section{Patient consent for publication}

Not applicable.

\section{Competing interests}

The authors declare that they have no competing interests.

\section{References}

1. Stanhewicz AE, Wenner MM and Stachenfeld NS: Sex differences in endothelial function important to vascular health and overall cardiovascular disease risk across the lifespan. Am J Physiol Heart Circ Physiol 315: H1569-H1588, 2018

2. Widlansky ME, Gokce N, Keaney JF Jr and Vita JA: The clinical implication of endothelial dysfunction. J Am Coll Cardiol 42: 1149-1160, 2003

3. Rajendran P, Rengarajan T, Thangavel J, Nishigaki $Y$, Sakthisekaran D, Sethi G and Nishigaki I: The vascular endothelium and human diseases. Int J Biol Sci 9: 1057-1069, 2013.

4. Sturtzel C: Endothelial cells. Adv Exp Med Biol 1003: 71-91, 2007.

5. Hergenreider E, Heydt S, Tréguer K, Boettger T, Horrevoets AJ, Zeiher AM, Scheffer MP, Frangakis AS, Yin X, Mayr M, et al: Atheroprotective communication between endothelial cells and smooth muscle cells through miRNAs. Nat Cell Biol Feb 14: 249-256, 2012
6. Huang AL and Vita JA: Effects of systemic inflammation on endothelium dependent vasodilation. Trends Cardiovasc Med 16: 15-20, 2006.

7. Kolluru GK, Bir SC and Kevil CG: Endothelial dysfunction and diabetes: Effects on angiogenesis, vascular remodeling, and wound healing. Int J Vasc Med 2012: 918267, 2012.

8. Park KH and Park WJ: Endothelial dysfunction: Clinical implication in cardiovascular disease and therapeutic approaches. J Korean Med Sci 30: 1213-1225, 2015.

9. Zhong L, Simard MJ and Huot J: Endothelial microRNAs regulating the NF- $\kappa \mathrm{B}$ pathway and cell adhesion molecules during inflammation. FASEB J 32: 4070-4084, 2018.

10. Onishi A, St Ange K, Dordick JS and Linhardt RJ: Heparin and anticoagulation. Front Biosci (Landmark Ed) 21: 1372-1392, 2016.

11. Ong CS, Marcum JA, Zehr KJ and Cameron DE: A century of heparin. Ann Thorac Surg 108: 955-958, 2019.

12. McLaughlin K, Nadeem L, Wat J, Baczyk D, Lye SJ and Kingdom JC: Low molecular weight heparin promotes transcription and release of placental growth factor from endothelial cells. Am J Physiol Heart Circ Physiol 318: H1008-H1017, 2019.

13. Chen J, Wang H, Gao C, Liu D, Fan Y, Li W, Chen Y and Pan S: Tetramethylpyrazine alleviates LPS-induced inflammatory injury in HUVECs by inhibiting Rho/ROCK pathway. Biochem Biophys Res Commun 514: 329-335, 2019.

14. Livak KJ and Schmittgen TD: Analysis of relative gene expression data using real-time quantitative PCR and the 2(-Delta Delta $\mathrm{C}(\mathrm{T}))$ method. Methods 25: 402-408, 2001.

15. Haarmann R, Ibrahim M, Stevanovic M, Bredemeier R and Schleiff E: The properties of the outer membrane localized Lipid A transporter LptD. J Phys Condens Matter 22: 454124, 2010.

16. Wan X, Wang PX, Zhou L and Xiang Q: Gene expression of toll-like receptors in the liver, lungs and spleen in mice after endotoxin challenge. Zhongguo Wei Zhong Bing Ji Jiu Yi Xue 16: 73-76, 2004 (In Chinese)

17. Zhang J, Zheng Y, Luo Y, Du Y, Zhang X and Fu J: Curcumin inhibits LPS-induced neuroinflammation by promoting microglial M2 polarization via TREM2/ TLR4/ NF- $\kappa \mathrm{B}$ pathways in BV2 cells. Mol Immunol 116: 29-37, 2019.

18. Xiao Q, Zhu X, Yang S, Wang J, Yin R, Song J, Ma A and Pan X: LPS induces CXCL16 expression in HUVECs through the miR-146a-mediated TLR4 pathway. Int Immunopharmacol 69: 143-149, 2019.

19. Li Y, Zhu H, Wei X, Li H, Yu Z, Zhang H and Liu W: LPS induces HUVEC angiogenesis in vitro through miR-146a-mediated TGF- $\beta 1$ inhibition. Am J Transl Res 15: 591-600, 2017.

20. Cox D, Kerrigan SW and Watson SP: Platelets and the innate immune system: Mechanisms of bacterial-induced platelet activation. J Thromb Haemost 9: 1097-1107, 2011.

21. Cheng X, Yang YL, Yang H, Wang YH and Du GH: Kaempferol alleviates LPS-induced neuroinflammation and BBB dysfunction in mice via inhibiting HMGB1 release and down-regulating TLR4/MyD88 pathway. Int Immunopharmacol 6: 29-35, 2018.

22. Gu J, Su S, Guo J,Zhu Y,Zhao M and Duan JA: Anti-inflammatory and anti-apoptotic effects of the combination of Ligusticum chuanxiong and Radix Paeoniae against focal cerebral ischaemia via TLR4/MyD88/MAPK/NF- $\mathrm{BB}$ signalling pathway in MCAO rats. J Pharm Pharmacol 70: 268-277, 2018.

23. Li C, Ai G, Wang Y, Lu Q, Luo C, Tan L, Lin G, Liu Y, Li Y, Zeng H, et al: Oxyberberine, a novel gut microbiota-mediated metabolite of berberine, possesses superior anti-colitis effect: Impact on intestinal epithelial barrier, gut microbiota profile and TLR4-MyD88-NF-кB pathway. Pharmacol Res 152: 104603, 2020.

24. LiH,Zhong X,LiW and Wang Q:Effects of 1,25-dihydroxyvitamin D3 on experimental periodontitis and AhR/NF- $\mathrm{B} / \mathrm{NLRP} 3$ inflammasome pathway in a mouse model. J Appl Oral Sci 27: e20180713, 2019.

25. Kim SY, Jin CY, Kim CH, Yoo YH, Choi SH, Kim GY, Yoon HM, Park HT and Choi YH: Isorhamnetin alleviates lipopolysaccharide-induced inflammatory responses in BV2 microglia by inactivating NF- $\kappa \mathrm{B}$, blocking the TLR4 pathway and reducing ROS generation. Int J Mol Med 43: 682-692, 2019.

26. Kim DC, Quang TH, Oh H and Kim YC: Steppogenin isolated from Cudrania tricuspidata shows Antineuroinflammatory effects via NF- $\kappa B$ and MAPK pathways in LPS-Stimulated BV2 and primary rat microglial cells. Molecules 22: 2130, 2017. 
27. Yu X, Lan P, Hou X, Han Q, Lu N, Li T, Jiao C, Zhang J, Zhang C and Tian Z: HBV inhibits LPS-induced NLRP3 inflammasome activation and IL-1 $\beta$ production via suppressing the $N F-\kappa B$ pathway and ROS production. J Hepatol 66: 693-702, 2017.

28. Kauppinen A, Suuronen T, Ojala J, Kaarniranta K and Salminen A: Antagonistic crosstalk between NF- $\mathrm{BB}$ and SIRT1 in the regulation of inflammation and metabolic disorders. Cell Signal 25: 1939-1948, 2013.

29. Pober JS and Sessa WC: Evolving functions of endothelial cells in inflammation. Nature Rev Immunol 7: 803-815, 2007.

30. Incalza MA, D'Oria R, Natalicchio A, Perrini S, Laviola L and Giorgino F: Oxidative stress and reactive oxygen species in endothelial dysfunction associated with cardiovascular and metabolic diseases. Vascul Pharmacol 100: 1-19, 2018.
31. Bischoff J: Endothelial-to-mesenchymal transition. Circ Res 124: 1163-1165, 2019.

32. Deanfield JE, Halcox JP and Rabelink TJ: Endothelial function and dysfunction: Testing and clinical relevance. Circulation 115: 1285-1295, 2007.

(i) (-) $€$ This work is licensed under a Creative Commons Attribution-NonCommercial-NoDerivatives 4.0 International (CC BY-NC-ND 4.0) License. 